\title{
The relationship between components of tumour inflammatory cell infiltrate and clinicopathological factors and survival in patients with primary operable invasive ductal breast cancer
}

\author{
ZMA Mohammed", ${ }^{*}$, , JJ Going ${ }^{3}$, J Edwards ${ }^{3}$, B Elsberger ${ }^{3}$, JC Doughty ${ }^{4}$ and DC McMillan' \\ 'University Department of Surgery, Academic Unit of Surgery, College of Medical, Veterinary and Life of Sciences - University of Glasgow, Royal Infirmary, \\ Glasgow G3I 2ER, UK; ${ }^{2}$ University Departments of Pathology, College of Medical, Veterinary and Life of Sciences - University of Glasgow, Royal and \\ Western Infirmaries, Glasgow, UK; ${ }^{3}$ Department of Pathology, Unit of Experimental Therapeutics, Institute of Cancer, College of Medical, Veterinary and \\ Life Sciences, Western Infirmary, Glasgow, UK; ${ }^{4}$ Department of Surgery, Western Infirmary, Glasgow GII 6NT, UK
}

BACKGROUND: The importance of the components of host local inflammatory response in determining outcome in primary operable ductal invasive breast cancer is not clear. The aim of this study was to examine the relationship between components of the tumour inflammatory cell infiltrate and standard clinicopathological factors including hormone status (oestrogen receptor (ER), progesterone receptor (PR) and human epidermal growth factor receptor (HER)-2), Ki-67 and survival in patients with primary operable invasive ductal breast cancer.

METHODS: Tumour inflammatory cell infiltrate, hormone status (ER, PR and HER-2), Ki-67 and standard clinicopathological factors were determined using routine pathological and immuno-histochemical techniques in 468 patients.

RESULTS: The large majority (94\%) of ductal tumours had evidence of inflammatory cell infiltrate. The general inflammatory cell infiltrate was positively associated with high grade $(P<0.00 \mathrm{I})$, the absence of $\mathrm{ER}(P<0.00 \mathrm{I})$, the absence of PR $(P<0.0 \mathrm{I})$, the presence of vascular invasion $(P<0.05)$ and high lymphocytic infiltrate, plasma cell infiltrate, other inflammatory cell infiltrate and macrophage infiltrate (all $P<0.001$ ). The median follow-up of the survivors was 165 months. During this period, 93 patients died of their cancer. On univariate analysis, stratified for ER status, tumour size $(P<0.0 \mathrm{I})$, lymph node involvement $(P<0.00 \mathrm{I})$, tumour plasma cell infiltrate $(P<0.001)$, other inflammatory cell infiltrate $(P<0.05)$ and treatment $(P<0.05)$ were associated with poorer cancer-specific survival whereas lymphocyte infiltrate $(P<0.001)$ was associated with improved cancer-specific survival. On multivariate analysis, stratified for ER status, lymph node involvement $(P<0.05)$ was independently associated with poorer cancer-specific survival whereas increased tumour lymphocyte infiltrate $(P<0.00 \mathrm{I})$ was independently associated with improved cancer-specific survival.

CONCLUSION: The results of this study show that, using routine histology, the general inflammatory cell infiltrate was a common feature and was positively associated with high grade, the absence of ER, the absence of PR, the presence of vascular invasion and high-grade infiltration of lymphocytes, plasma cells, other inflammatory cells and macrophages. Also, that within a mature cohort of patients, a high lymphocytic infiltrate was associated with improved survival, independent of clinicopathological characteristics including ER status, in primary operable ductal invasive breast cancer. These results rationalise previous work and provide a sound basis for future studies in this important area of breast cancer research.

British Journal of Cancer (2012) 1 07, 864-873. doi:I0.1038/bjc.20 I 2.347 www.bjcancer.com

Published online 9 August 2012

(c) 2012 Cancer Research UK

Keywords: primary ductal invasive breast cancer; hormone status; tumour inflammatory cell infiltrate; lymphocytes; plasma cells; survival

Breast cancer is the commonest cancer and the leading cause of cancer death in women. It accounts for $22 \%$ of all female cancers (Parkin et al, 2001). More than 42000 women in the United Kingdom are diagnosed with breast cancer each year and $\sim 80 \%$ survive at least 5 years (Cancerstats, 2008).

The prognosis of breast cancer is influenced by well recognised host and tumour related factors including patient age, histological type and grade, tumour size, lymph node status, oestrogen

*Correspondence: Dr ZMA Mohammed; E-mail: z.mohammed. I@research.gla.ac.uk Received 20 April 2012; revised 12 June 2012; accepted 10 July 2012; published online 9 August 2012 receptor (ER) and progesterone receptor (PR) status and human epidermal growth factor receptor 2 (HER-2) status (Lal et al, 2005). In addition, accumulating evidence indicate that lymphatic and blood vascular invasion are also significant prognostic factors for poorer survival for breast cancer (Lee et al, 1990; Gasparini et al, 1994; Kato et al, 2003).

There is now good evidence that the development of cancer and its progression are dependent on a complex interaction of the tumour and the host inflammatory response (Vakkila and Lotze, 2004; DeNardo and Coussens, 2007; Gottfried et al, 2008; Colotta et al, 2009; Hanahan and Weinberg, 2011). The role of the tumour inflammatory cell infiltrate in predicting survival in patients with primary operable breast cancer has recently been 
the subject of a systematic review (Mohammed et al, 2012b). They concluded that, despite the large number of studies and considerable effort over a 90-year period, the relationship between different aspects of tumour inflammatory cell infiltrate and outcome in primary operable breast cancer remains unclear. Indeed, a number of studies over these years have attempted to examine the relationship between the inflammatory infiltrate at the invasive margin and survival in operable breast cancer. However, there have been conflicting results, out of a total of 24 studies, 13 studies reported an association between inflammatory infiltrate and improved survival, 4 reported no association and 7 reported an association between inflammatory infiltrate and poorer survival. It was concluded that the inconsistencies in the literature were, in large part, due to the absence of methodological validation, underpowered studies (small sample size, cancer subtype heterogeneity and insufficient follow-up) and the absence of independent validation (Mohammed et al, 2012b).

Recently, Klintrup et al (2005) reported that a high-grade inflammatory reaction at the invasive margin predicts longer survival in patients undergoing potentially curative resection of colorectal cancer. In particular, they simplified and standardised the evaluation of the tumour inflammatory infiltrate by including all inflammatory cell types and classifying the infiltrate as either low or high grade. This approach has been independently validated in patients undergoing potentially curative resection for colorectal cancer (Roxburgh et al, 2009a, b). However, its prognostic value has not been examined in primary operable invasive ductal cancer.

Therefore, a logical starting point to examine the nature the tumour inflammatory cell infiltrate in operable breast cancer would be to examine simple routine pathology haematoxylin and eosin (H\&E) slides in a manner similar to that proposed by Klintrup et al (2005) and to determine its association with standard pathological criteria and outcome. Therefore, the aim of this study was to examine in routine histopathological sections the relationship between components of the tumour inflammatory cell infiltrate and standard clinicopathological factors including hormone status (ER, PR and HER-2), Ki-67, vascular invasion and survival in patients with primary operable invasive ductal breast cancer.

\section{PATIENTS AND METHODS}

Patients presenting with invasive ductal breast cancer at the Glasgow Royal and Western Infirmaries and the Stobhill Hospital, all in the West of Scotland, between 1995 and 1998 were studied $(n=468)$. Clinicopathological data included age, histological tumour type, grade, tumour size, lymph node status, vascular invasion, type of surgery and use of adjuvant treatment (chemotherapy, hormonal therapy and radiotherapy). The data was retrieved from the routine reports and all features were reported by qualified specialist pathologists. ER, PR, HER-2 status and Ki-67 immunohistochemical analyses was performed as previously described and the results of visual scoring were used in this study. The cutoffs for ER, PR and Ki-67 were 10\%, 10\% and $15 \%$, respectively (Mohammed et al, 2012a, 2012c). Human epidermal growth factor receptor-2 was reported according to national guidelines with in situ hybridisation for those who were $2+$ on immunohistochemistry (IHC) (Mohammed et al, 2012d). The inclusion of ductal breast cancers only was to limit the potential confounding effects of other tumour types on the analysis in this study.

Ethics committee approval for use of all human tissue specimens in this study was obtained under a protocol approved by the Research Ethics Committee of the North Glasgow University Hospitals NHS Trust.

\section{Methods}

Slide scanning and scoring Routine histopathological sections for the 468 patients were scanned at objective magnification $\times 40$ by Hamamatsu NanoZoomer (Hertfordshire, UK). Assessment of tumour inflammatory was performed on a computer monitor using the Slidepath Tissue IA system version 1.0 (Slidepath, Dublin, Ireland).

Assessment of tumour inflammatory cell infiltrate Scanned routine histopathological sections were used to score peritumoural inflammatory cell infiltrate according to Klintrup criteria. Klintrup scoring of slides was carried out as described (Klintrup et al, 2005). Briefly, tumours were scored on a 4 point scores based on appearances at the edge of tumour invasion. A score of 0 , signified there was no inflammatory cells at the tumour's invasive margin; score 1, indicated a mild and patchy inflammatory cells; score 2, denoted a prominent band-like inflammatory reaction at the invasive margin and score 3, revealed a florid cup-like inflammatory infiltrate at the invasive edge with frequent destruction of cancer cell islands (Figure 1). A total of 121 tumour specimens were scored independently for local inflammatory infiltration (tumour margin characteristics) by two observers (JJG and ZM) and the interclass correlation coefficients (ICCC) was 0.98 . The author (ZM) then scored all slides and these data were used in the analysis. These scores were then subsequently classified as absent or present.

In those patients with evidence of a tumour inflammatory cell infiltrate (present) a technique for the analysis of peritumoural inflammatory cell infiltrate was developed in consultation with a pathologist (JJG). To account for the variation within individual fields proportions of the tumour inflammatory cell infiltrate were estimated in a minimum of 4 to a maximum of 12 fields $(\times 40$, $0.6 \mathrm{~mm}$ in diameter) at the invasive margin on full-faced sections. Lymphocytes, neutrophils, eosinophils, basophils, plasma cells and mast cells had characteristic morphological features that allowed them to be recognised and counted in $H \& E$ full-faced sections. Carcinoma cells, stromal and endothelial cells, and cells undergoing necrosis were not counted. The mean percentage of each cell type in the four fields was calculated and used in the analysis. As a check on reproducibility of this approach, a total of 60 tumour specimens were scored independently for lymphocyte, neutrophils, eosinophils, basophils, plasma cells and mast cells infiltration by two observers (BE and ZM) with $\mathrm{ICCC}=0.85,0.91,0.96,0.97,0.87$ and 0.97, respectively. The author ( $\mathrm{ZM})$ then scored all slides and these data were used in the analysis.

IHC for macrophages Using the H\&E slides macrophages were difficult to identify reliably. Therefore, tissue microarray (TMA) and IHC were utilised to assess macrophages. The TMA samples were taken from the tumour as previously described (Mohammed et al, 2012c).

In the assessment of CD68 an important concern was whether the small core samples used in the TMA was representative of the tumour biopsy as a whole. To address this concern a pilot study of the comparison the scoring of full-face sections with the TMA sections was carried out in 35 patients.

Immunoreactivity to anti-CD68 + antibody was determined in 35 cases by using full-face tissue sections. TMAs were also utilised to assess macrophages for the 468 patients. Freshly cut 2.5 $\mu \mathrm{m}$ thick breast cancer full-face tissue sections and TMAs were stained for CD68+. Sections and cores were dewaxed and rehydrated. Antigen retrieval for $\mathrm{CD} 68+$ were performed by keeping the slides in Tris EDTA buffer ( $\mathrm{pH} 8$ ), in a pressure cooker for $7 \mathrm{~min}$. Endogeneous peroxidise was locked by incubation in $3 \%$ hydrogen peroxide for $20 \mathrm{~min}$. The slides were then incubated with the normal horse serum at dilution $1: 10$ for $30 \mathrm{~min}$ at $25^{\circ} \mathrm{C}$ to block nonspecific-binding sites. Primary antibody for CD68+ (Monoclonal mouse anti-human, CD68+, Clone PG-M1, Code 


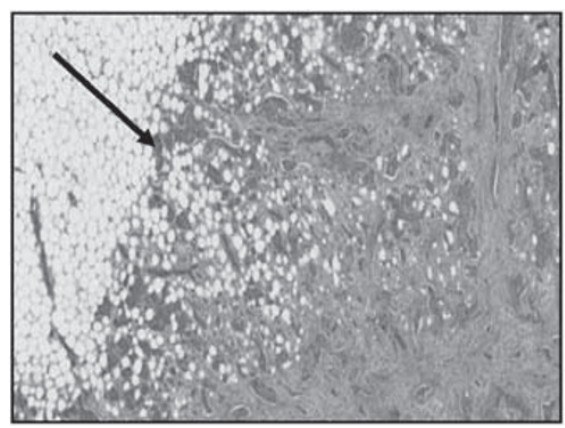

$0=$ No inflammatory infiltrate

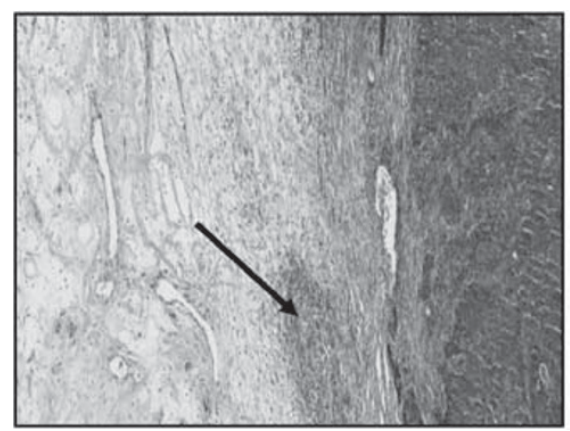

2 = Moderate inflammatory infiltrate

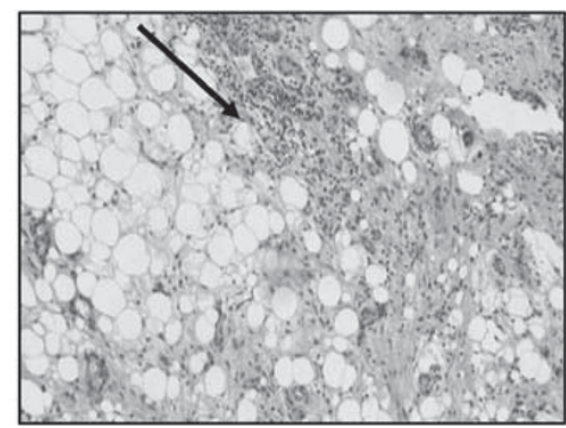

1 = Mild inflammatory infiltrate

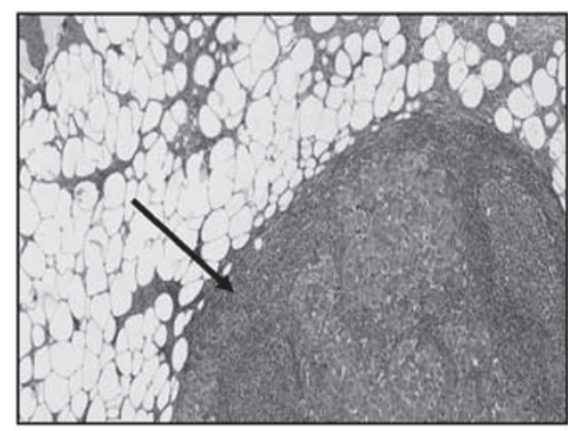

$3=$ Severe inflammatory infiltrate

Figure I Scoring of general inflammatory infiltrate at the invasive margin (Klintrup criteria).

M0876, Dako, Glostrup, Denmark) was added with dilution $1: 200$ for $60 \mathrm{~min}$ at room temperature. Sites of binding were detected using the Envision technique (Dako, code K5007) with 3-3' diaminobenzidine (Vector, code SK 4001, Burlingame, CA, USA), a chromogenic substrate, according to the manufacturer's instruction. Slides were counterstained with haematoxylin, dehydrated and mounted with DPX. Two full sections of tonsil tissue were used as positive and negative controls for each set of staining as tonsil had previously shown to have a high CD68 + content, by IHC.

Assessment of CD68 $\pm \quad C D 68+$ scoring in full-face tissue sections and in TMA was based on a modification of the method described by Mahmoud et al (2012) in which the number of macrophages was counted. In the full-face tissue sections, CD68 + was counted in three $\times 20$ fields and the mean for the three fields was calculated. In TMA CD68 + was counted in the three cores and the mean for the three cores was calculated. The mean for the three fields in full-face sections was compared with the mean of three cores in TMA for the same patients. The ICCC was 0.94, which indicates excellent agreement.

In total, 180 cores were independently scored for CD68 + by two observers (JJG and ZM) blinded patient outcome and the other observer's score. The ICCC was 0.80 , which indicates excellent agreement. The author (ZM) then scored all slides and these data were used in subsequent analysis.

Patients underwent regular follow-up ( 3 months, 6 months and then yearly to 5 years) with yearly CT scanning and regular X-ray mammography surveillance until 10 years post surgery. Information on date and cause of death was checked with that received by the Cancer Registry system and the Registrar General (Scotland).

Statistical analysis For the purpose of analysis, the percentage of tumour lymphocyte, the plasma cell and other inflammatory cells were examined using the interobserver interclass correlation coefficient was performed using reliability analysis. Interrelationships between variables were assessed using contingency table
Table I The clinicopathological characteristics of patients with primary operable invasive ductal breast cancer $(n=468)$

\begin{tabular}{|c|c|}
\hline Clinicopathological characteristics & Patients ( $n$ ) \\
\hline Age $(\leqslant 50 />50$ years $)$ & $138(30 \%) / 330$ (70\%) \\
\hline Size $(\leqslant 20 / 21-50 />50 \mathrm{~mm})$ & $\begin{array}{c}280(60 \%) / / 74(37 \%) / \\
13(3 \%)\end{array}$ \\
\hline Grade $(\mid / / 1 / 1 \| 1)$ & $\begin{array}{c}94(20 \%) / 182(39 \%) / \\
192(41 \%)\end{array}$ \\
\hline Involved lymph node $(0 / 1-3 />3)$ & $\begin{array}{c}253(54 \%) / 132(28 \%) / \\
78(17 \%)\end{array}$ \\
\hline Oestrogen-receptor status (ER - /ER + ) & $159(34 \%) / 283(61 \%)$ \\
\hline Progesterone-receptor status $(\mathrm{PR}-/ \mathrm{PR}+)$ & $243(52 \%) / 202(43 \%)$ \\
\hline HER-2 status (HER-2 - /HER-2 +) & $370(79 \%) / 73(16 \%)$ \\
\hline Ki-67 status (low Ki-67/high Ki-67) & $335(72 \%) / 104$ (22\%) \\
\hline Lymphovascular invasion (absent/present) & $203(43 \%) / 17 \mid(37 \%)$ \\
\hline $\begin{array}{l}\text { General inflammatory infiltrate (None/mild/ } \\
\text { moderate/severe) }\end{array}$ & $\begin{array}{c}30(6 \%) / 313(67 \%) / 104 \\
(22 \%) / 21(5 \%)\end{array}$ \\
\hline $\begin{array}{l}\text { Loco-regional treatment (Lumpectomy } \pm \text { radiotherapy/ } \\
\text { mastectomy } \pm \text { radiotherapy) }\end{array}$ & $179(38 \%) / 289(62 \%)$ \\
\hline $\begin{array}{l}\text { Systemic treatment (ER-based treatment; hormonal/ } \\
\text { hormonal + chemotherapy/chemotherapy/none) }\end{array}$ & $\begin{array}{l}238(51 \%) / 92(20 \%) / \\
101(22 \%) / 29(6 \%)\end{array}$ \\
\hline
\end{tabular}

Abbreviations: ER = oestrogen receptor; HER-2 = human epidermal growth factor receptor-2; $\mathrm{PR}=$ progesterone receptor.

analysis with the $\chi^{2}$ test for trend as appropriate. Univariate and multivariate survival analysis with calculation of hazard ratios (HRs) and 95\% confidence interval (95\% CI) were performed using the Cox proportional hazards model. A stepwise backward procedure was used to derive a final model of the variables that had a significant independent relationship with survival. Deaths up to March 2010 were included in the analysis. Because of the number of statistical comparisons, a $P$-value $<0.01$ was considered to be significant. All statistical analysis was performed using the SPSS software version 19 (SPSS Inc., Chicago, IL, USA). 


\section{RESULTS}

Baseline clinicopathological characteristics of the patients with primary operable ductal invasive breast cancer $(n=468)$ are shown in Table 1.

Relationships between inflammatory cell infiltrate and clinicopathological characteristics are shown in Table 2. Patients who had tumour with inflammatory cell infiltrate had higher tumour grade $(P<0.001)$, more ER-negative tumours $(P<0.001)$, more PRnegative tumours $(P<0.01)$, the presence of vascular invasion $(P<0.05)$, higher percentage of lymphocyte cell infiltrate at the invasive margin $(P<0.001)$, higher percentage of plasma cell infiltrate at the invasive margin $(P<0.001)$ and higher percentage of other inflammatory cell infiltrate (neutrophils, eosinophils, basophils and mast cells) at the invasive margin $(P<0.001)$.
Relationships between ER status and clinicopathological characteristics are shown in Table 3. Patients with ER-negative tumours were younger $(P<0.01)$, had larger tumour size $(P<0.001)$, higher tumour grade $(P<0.001)$, more lymph node involvement $(P<0.05)$, more $P R$-negative tumours $(P<0.001)$, more HER-2-positive tumours $(P<0.001)$, the presence of vascular invasion $(P<0.001)$, severe inflammatory infiltrate at the invasive margin $(P<0.001)$, lower percentage of lymphocyte cell infiltrate at the invasive margin $(P<0.001)$, higher percentage of plasma cell infiltrate at the invasive margin $(P<0.001)$, higher percentage of other inflammatory cell infiltrate at the invasive margin $(P<0.001)$, higher CD68 $+(P<0.001)$, were more likely to receive adjuvant treatment in the form of endocrine therapy and/or chemotherapy $(P<0.001)$ and had a shorter cancer-specific survival $(P<0.001)$. To account for the major confounding effect

Table 2 The relationship between inflammatory cell infiltrate and clinicopathological characteristics of patients with primary operable invasive ductal breast cancer

\begin{tabular}{|c|c|c|c|}
\hline & $\begin{array}{l}\text { No inflammatory cell } \\
\text { infiltrate }(n=30)\end{array}$ & $\begin{array}{l}\text { Inflammatory cell } \\
\text { infiltrate }(n=438)\end{array}$ & (P-value) \\
\hline Age $(\leqslant 50 />50$ years $)$ & $5 / 25$ & 133/305 & 0.112 \\
\hline Grade $(|/| / / / I I)$ & $12 / 14 / 4$ & $82 / 168 / 188$ & $<0.001$ \\
\hline Involved lymph node $(0 / 1-3 />3)$ & 19/7/4 & $234 / 125 / 74$ & 0.361 \\
\hline Oestrogen-receptor status (ER - /ER + ) & $0 / 29$ & 159/254 & $<0.001$ \\
\hline HER-2 status (HER-2 - /HER-2 +) & $25 / 3$ & $345 / 70$ & 0.396 \\
\hline Ki-67 status (low Ki-67/high Ki-67) & $21 / 5$ & $314 / 99$ & 0.582 \\
\hline Vascular invasion (absent/present) & $20 / 6$ & $183 / 165$ & 0.016 \\
\hline \% Tumour lymphocyte infiltrate (median, range) & 0 & $98(0-100)$ & $<0.001$ \\
\hline \% Tumour plasma cell infiltrate (median, range) & 0 & । (0-90) & $<0.001$ \\
\hline$\%$ Other inflammatory cell infiltrate (median, range) & 0 & $0(0-85)$ & $<0.001$ \\
\hline Cancer-specific survival (months) ${ }^{\mathrm{a}}$ & $134(109-159)$ & $152(\mid 47-157)$ & 0.098 \\
\hline
\end{tabular}

Abbreviations: $\mathrm{Cl}=$ confidence interval; $\mathrm{ER}=$ oestrogen receptor; HER-2 = human epidermal growth factor receptor-2; $\mathrm{PR}=$ progesterone receptor. ${ }^{\mathrm{a}}$ Mean $(95 \% \mathrm{Cl})$.

Table 3 The relationship between clinicopathological characteristics and ER status of patients with primary operable invasive ductal breast cancer

\begin{tabular}{|c|c|c|c|}
\hline Age $(\leqslant 50 />50$ years $)$ & $59 / 100$ & $66 / 217$ & 0.002 \\
\hline Grade $(\mid / / / / I I)$ & $6 / 25 / / 128$ & $80 / 147 / 56$ & $<0.001$ \\
\hline Involved lymph node $(0 / \mid-3 />3)$ & $83 / 38 / 37$ & $160 / 83 / 36$ & 0.042 \\
\hline Progesterone-receptor status (PR - /PR + ) & $151 / 6$ & $88 /|9|$ & $<0.001$ \\
\hline HER-2 status (HER-2 - /HER-2 +) & $109 / 47$ & $253 / 26$ & $<0.001$ \\
\hline General inflammatory cell infiltrate (absent/present) & $0 / 159$ & $29 / 254$ & $<0.001$ \\
\hline \% Tumour lymphocyte infiltrate (median, range) & $95(4-100)$ & $98(0-100)$ & $<0.001$ \\
\hline \% Tumour plasma cell infiltrate (median, range) & $2(0-90)$ & I (0-90) & $<0.001$ \\
\hline$\%$ Other inflammatory cell infiltrate (median, range) & $\mid(0-4 \mid)$ & $0(0-85)$ & $<0.001$ \\
\hline Macrophages (median, range) & $145(\mid 6-619)$ & $116(14-450)$ & 0.001 \\
\hline Loco-regional treatment (Lumpectomy \pm radiotherapy/mastectomy \pm radiotherapy) & $58 / 101$ & $112 / 17 \mid$ & 0.521 \\
\hline
\end{tabular}

Abbreviations: $\mathrm{Cl}=$ confidence interval; $\mathrm{ER}=$ oestrogen receptor; HER-2 = human epidermal growth factor receptor-2; $\mathrm{PR}=$ progesterone receptor. ${ }^{\mathrm{a}} \mathrm{Mean}$ ( $95 \% \mathrm{Cl}$ ). 
of ER status on clinicopathological characteristics and the tumour inflammatory cell infiltrate analysis was subsequently stratified according to ER status.

Minimum follow-up was 142 months; the median follow-up of the survivors was 165 months. In the patients with ER-negative tumours, 57 patients developed recurrence, 8 local, 38 distant and 3 both, 78 patients died, 47 of their disease. In the ER-positive tumours, 44 patients developed recurrence, 8 local, 30 distant and 1 both, 117 patients disease.

According to Figure 1A general inflammatory cell infiltrate was split to absent and present (Figure 2A for ER negative and B for ER positive). As there appears to be no consistent and well defined cutoffs for tumour lymphocyte infiltrate, tumour plasma cells infiltrate or other inflammatory cells infiltrate, the data were split into tertiles. On inspection of the survival curves for these tertiles (Figure 1B-D), for tumour lymphocytic infiltrate and to simplify the analysis for subsequent validation, the first tertile was taken as 'low' and the second and third tertiles were grouped as 'high' whereas for tumour plasma cells infiltrate and other inflammatory cells infiltate the first and second tertiles were grouped as 'low' and the third tertile was taken as 'high'. This yielded a cutoff of $<96 /$ $\geqslant 96 \%$ for low and high tumour lymphocyte infiltrate and of $<3 /$ $\geqslant 3 \%$ for tumour plasma cells infiltrate and other inflammatory cells infiltrate. These cutoffs were examined with cancer-specific survival for ER-negative (Figures 3C, E and G) and for ER positive (Figures 3D, F and $\mathrm{H}$ ).

The relationship between clinicopathological characteristics of patients with ER-negative primary operable invasive ductal breast cancer and recurrence-free survival was examined. On univariate survival analysis, tumour size (HR 2.50, 95\% CI 1.39-4.39, $P=0.002$ ), lymph node involvement (HR 1.67, 95\% CI $1.19-2.35, P=0.003$ ), vascular invasion (HR 2.67, 95\% CI $1.25-$ $5.69, P=0.011$ ), plasma cell infiltrate (HR 3.25, 95\% CI $1.75-6.04$, $P<0.001$ ) and other inflammatory cells infiltrate (HR 2.09, 95\% CI 1.16-3.77, $P=0.014$ ) were significantly associated with poorer recurrence-free survival. Lymphocyte infiltrate (HR 0.34, 95\% CI $0.18-0.63, P=0.001$ ) and macrophage infiltrate (HR 0.52, 95\% CI $0.33-0.81, P=0.004)$ were significantly associated with improved recurrence-free survival. On multivariate survival analysis, tumour size (HR 5.30, 95\% CI 1.79-15.71, $P=0.003$ ) was independently associated with poorer recurrence-free survival. Lymphocyte infiltrate (HR $0.31,95 \%$ CI $0.13-0.74, P=0.008$ ) and macrophage infiltrate (HR $0.50,95 \%$ CI $0.30-0.82, P=0.007$ ) were independently associated with improved recurrence-free survival for patients with ER-negative tumours.

The relationships between clinicopathological characteristics of patients with ER-negative primary operable invasive ductal breast cancer and cancer-specific survival are shown in Table 4 . Tumour size $(P<0.01)$, lymph node involvement $(P<0.001)$, vascular invasion $(P<0.05)$, plasma cell infiltrate $(P<0.001)$, other inflammatory cells infiltrate $(P<0.01)$ and loco-regional treatment $(P<0.01)$ were significantly associated with poorer cancer-specific survival. Lymphocyte infiltrate $(P<0.001)$ and CD68 $+(P<0.01)$ were significantly associated with improved cancer-specific survival for patients with ER-negative tumours. On multivariate survival analysis, lymph node involvement $(P<0.05)$, other inflammatory cells infiltrate $(P<0.05)$ and loco-regional treatment $(P<0.0)$ were significant independent predictors of poorer cancer-specific survival. Lymphocyte infiltrate $(P<0.01)$ and $\mathrm{CD} 68+(P<0.001)$ were significant independent predictors of improved cancer-specific survival for patients with ER-negative tumours.

The relationship between clinicopathological characteristics of patients with ER-positive primary operable invasive ductal breast cancer and recurrence-free survival was examined. On univariate survival analysis, tumour grade (HR 2.12, 95\% CI 1.29-3.50, $P=0.003$ ), lymph node involvement (HR 2.82, 95\% CI 1.84-4.33, $P<0.001$ ), HER-2 status (HR 2.90, 95\% CI 1.26-7.62, $P=0.012$ ),
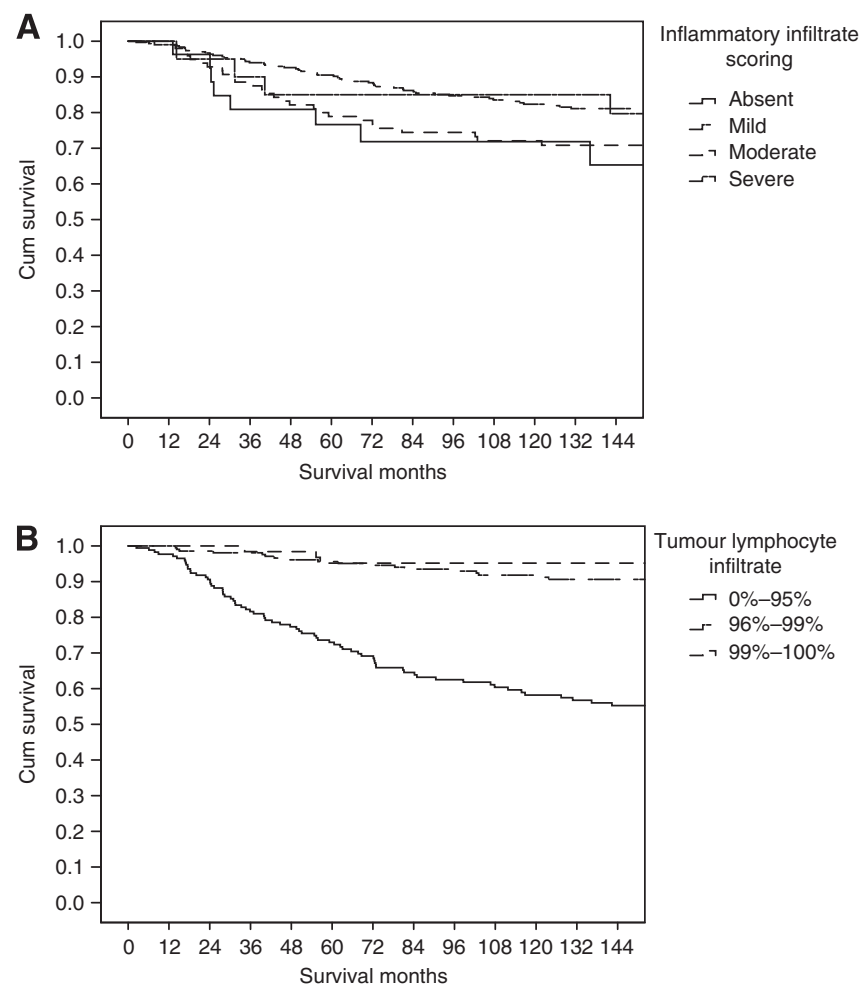

C

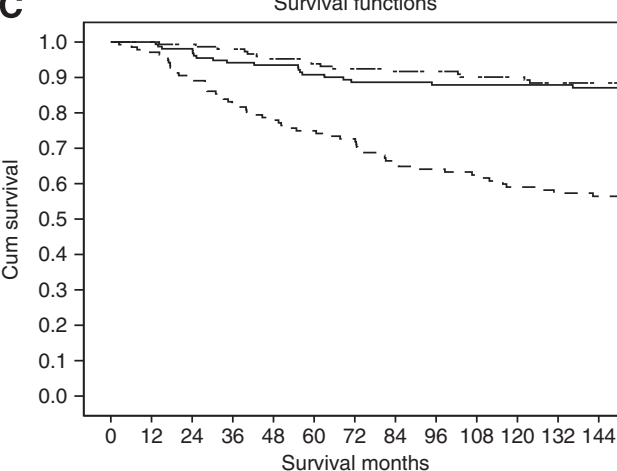

umour plasma cells infiltrate $\rightarrow 0 \%$ - $1 \%-2 \%$ - ᄀ $3 \%-90 \%$

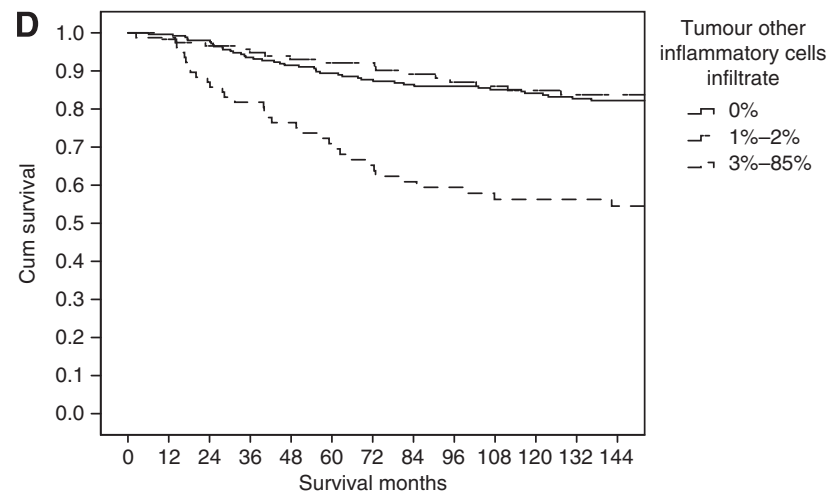

Figure 2 The relationship between general inflammatory infiltrate $(\mathbf{A})$ tumour lymphocyte infiltrate (B), tumour plasma cell infiltrate $(\mathbf{C})$ and other inflammatory cell infiltrate (D), using tertiles and cancer-specific survival in all patients with invasive ductal breast cancer.

Ki-67 proliferative activity (HR 3.27, 95\% CI 1.69-6.65, $P<0.001$ ), vascular invasion (HR 5.93, 95\% CI $2.54-13.83, P<0.001$ ) and local-regional treatment (HR 2.42, 95\% CI 1.10-5.33, $P=0.028$ ) 

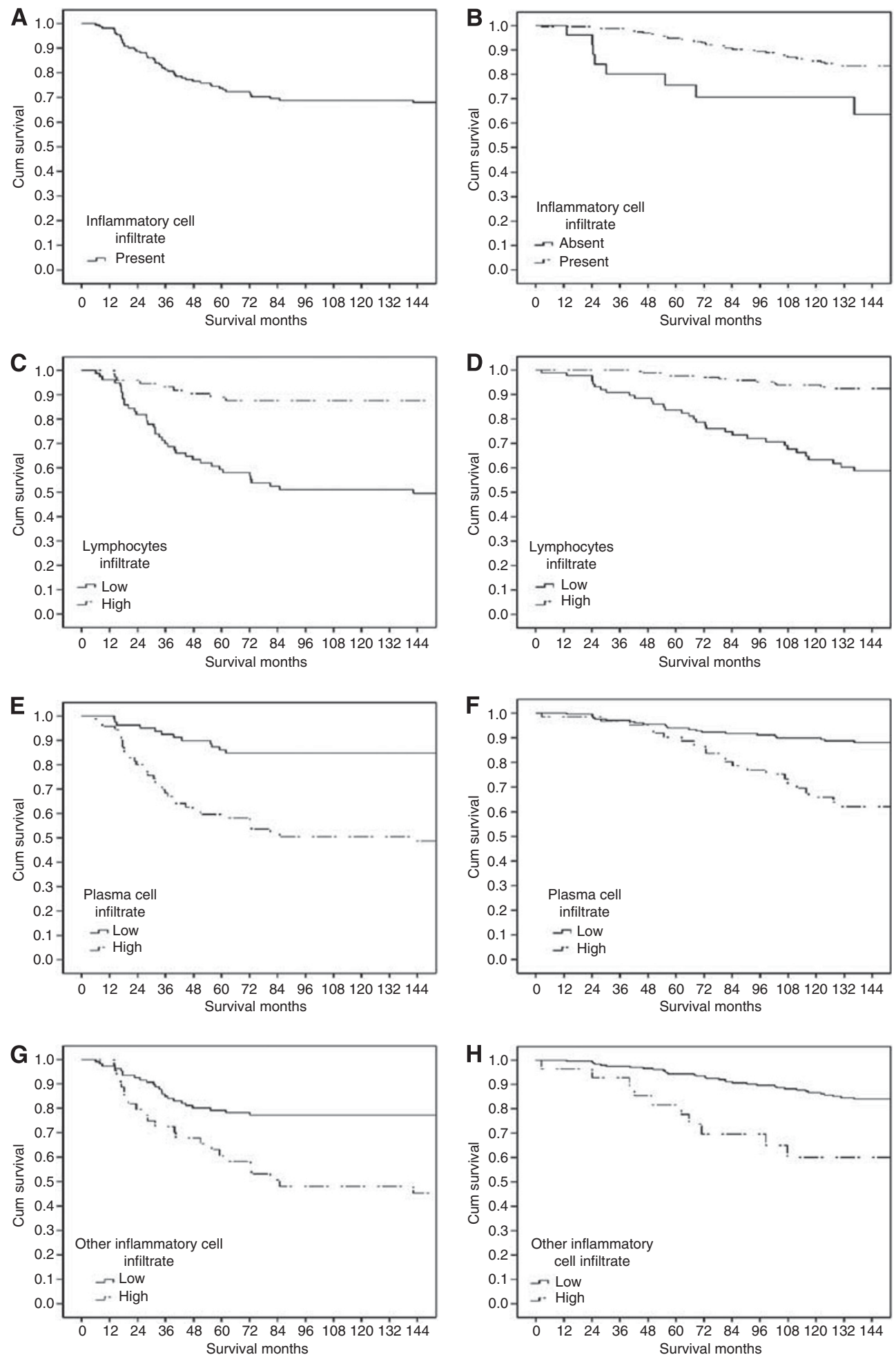

Figure 3 The relationship between general inflammatory cell infiltrate ( $\mathbf{A}$ for $E R-$ and $\mathbf{B}$ for $E R+)$, lymphocytes infiltrate $(\mathbf{C}$ for $E R-$ and $\mathbf{D}$ for $E R+)$, tumour plasma cell infiltrate (E for ER - and $\mathbf{F}$ for $E R+$ ), and other inflammatory cell infiltrate $(\mathbf{G}$ for $E R$ - and $\mathbf{H}$ for ER + ) and cancer-specific survival in all patients with invasive ductal breast cancer.

were significantly associated with poorer recurrence-free survival. Lymphocyte infiltrate (HR $0.37,95 \%$ CI $0.19-0.72, P=0.003$ ) was significantly associated with improved recurrence-free survival. On multivariate survival analysis, lymph node involvement (HR 2.14, 95\% CI 1.26-3.63, $P=0.005$ ), HER-2 status (HR 2.46, $95 \%$ CI $1.00-6.05, \quad P=0.049), \quad$ Ki-67 proliferative activity
(HR 4.58, 95\% CI 2.02-10.42, $P<0.001$ ), vascular invasion (HR $4.01,95 \%$ CI $1.45-11.10, P=0.007$ ) and other inflammatory cell infiltrate (HR 5.03, 95\% CI 1.95-13.00, $P=0.001$ ) were independently associated with poorer recurrence-free survival. The presence of PR (HR 0.38, 95\% CI $0.17-0.86, P=0.020$ ) and general inflammatory cell infiltrate (HR $0.10,95 \%$ CI $0.04-0.29$, 
Table 4 The relationship between clinicopathological characteristics of patients with ER-negative primary operable invasive ductal breast cancer and cancer-specific survival

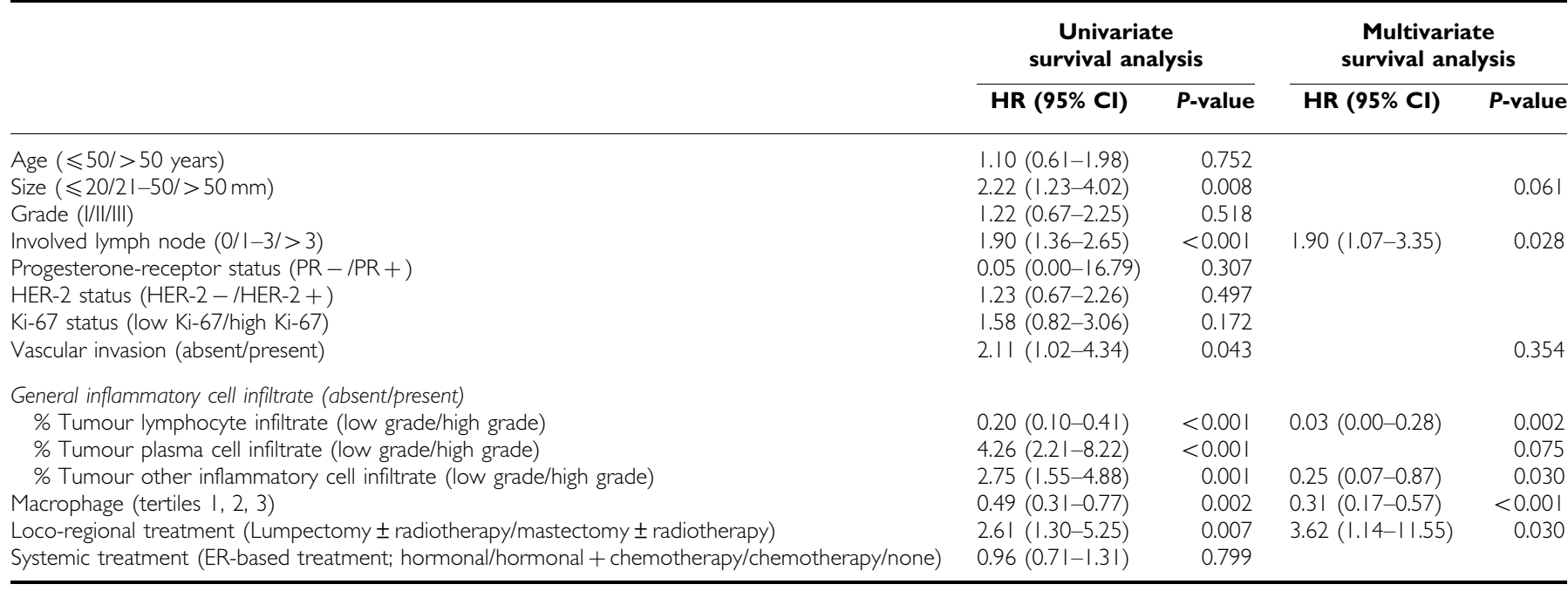

Abbreviations: $\mathrm{Cl}=$ confidence interval; $\mathrm{ER}=$ oestrogen receptor; HER-2 = human epidermal growth factor receptor-2; $\mathrm{HR}=$ hazard ratio; $\mathrm{PR}=$ progesterone receptor.

Table 5 The relationship between clinic-pathological characteristics of patients with ER-positive primary operable invasive ductal breast cancer and cancer-specific survival

\begin{tabular}{|c|c|c|c|c|}
\hline & \multicolumn{2}{|c|}{$\begin{array}{c}\text { Univariate } \\
\text { survival analysis }\end{array}$} & \multicolumn{2}{|c|}{$\begin{array}{c}\text { Multivariate } \\
\text { survival analysis }\end{array}$} \\
\hline & HR (95\% Cl) & $P$-value & HR (95\% Cl) & $P$-value \\
\hline Size $(\leqslant 20 / 21-50 />50 \mathrm{~mm})$ & $2.23(1.37-3.62)$ & 0.001 & & 0.150 \\
\hline Grade $(|/| / / / I I)$ & $1.93(1.26-2.97)$ & 0.003 & & 0.109 \\
\hline Involved lymph node $(0 / \mid-3 />3)$ & $2.47(1.70-3.58)$ & $<0.001$ & $1.89(1.18-3.03)$ & 0.008 \\
\hline Ki-67 status (low Ki-67/high Ki-67) & $4.19(2.30-7.63)$ & $<0.001$ & $5.57(2.73-11.36)$ & $<0.001$ \\
\hline Vascular invasion (absent/present) & $4.42(2.26-8.68)$ & $<0.001$ & $2.60(1.11-6.10)$ & 0.027 \\
\hline General inflammatory cell infiltrate (absent/present) & $0.34(0.16-0.72)$ & 0.005 & $0.26(0.09-0.72)$ & 0.009 \\
\hline \% Tumour lymphocyte infiltrate (low grade/high grade) & $0.13(0.07-0.26)$ & $<0.001$ & $0.15(0.07-0.33)$ & $<0.001$ \\
\hline \% Tumour plasma cell infiltrate (low grade/high grade) & $3.53(1.97-6.29)$ & $<0.00$ I & & 0.708 \\
\hline \% Tumour other inflammatory cell infiltrate (low grade/high grade) & $3.49(1.77-6.89)$ & $<0.001$ & & 0.171 \\
\hline
\end{tabular}

Abbreviations: $\mathrm{Cl}=$ confidence interval; $\mathrm{ER}=$ oestrogen receptor, $\mathrm{HER}-2=$ human epidermal growth factor receptor-2; $\mathrm{HR}=$ hazard ratio; $\mathrm{PR}=$ progesterone receptor.

$P<0.001)$ were independently associated with improved recurrence-free survival.

The relationships between clinicopathological characteristics of patients with ER-positive primary operable invasive ductal breast cancer and cancer-specific survival are shown in Table 5. Tumour size $(P<0.01)$, tumour grade $(P<0.01)$, lymph node involvement $(P<0.001)$, Ki-67 proliferative activity $(P<0.001)$, vascular invasion $(P<0.001)$, plasma cell infiltrate $(P<0.001)$, other cells infiltrate $(P<0.001)$ and loco-regional treatment $(P<0.05)$ were significantly associated with poorer cancer-specific survival. General inflammatory cell infiltrate $(P<0.01)$ and lymphocyte infiltrate $(P<0.001)$ were significantly associated with improved cancer-specific survival. On multivariate survival analysis, patient's age $(P<0.05)$, lymph node involvement $(P<0.01)$, HER-2 status $(P<0.05)$, Ki-67 proliferative activity $(P<0.001)$ and vascular invasion $(P<0.05)$ were significant independent predictors of poorer cancer-specific survival. Inflammatory cell infiltrate $(P<0.01)$ and lymphocyte infiltrate $(P<0.001)$ were significant independent predictors of improved cancer-specific survival for patients with ER-positive tumours.
The interrelationships between clinicopathological characteristics for patients with ER-negative primary operable invasive ductal breast cancer are shown in Table 6 . Increased tumour size was positively associated with more lymph node involvement $(P<0.01)$. Higher tumour grade was positively associated with PR status $(P<0.01)$. Lymph node involvement was positively associated vascular invasion $(P<0.001)$. HER-2 status was positively associated with vascular invasion $(P<0.01)$. Lymphocyte infiltrate was negatively associated with plasma cell infiltrate $(P<0.001)$ and other inflammatory cells infiltrate $(P<0.001)$. Plasma cell infiltrate was positively associated with other inflammatory cells infiltrate $(P<0.001)$.

The interrelationships between clinicopathological characteristics for patients with ER-positive primary operable invasive ductal breast cancer are shown in Table 7. Increased tumour size was positively associated with more involved lymph node $(P<0.001)$, high Ki-67 proliferative activity $(P<0.01)$ and vascular invasion $(P<0.001)$. Higher tumour grade was positively associated with HER-2 + status $(P<0.001)$, Ki-67 proliferative activity $(P<0.001)$, vascular invasion $(P<0.001)$ and CD68 $+(P<0.01)$. Lymph node involvement was positively associated with vascular invasion 
Table 6 Interrelationships between the clinicopathological characteristics in patients with ER-negative primary operable invasive ductal breast cancer $(n=159)$

\begin{tabular}{|c|c|c|c|c|c|c|c|c|c|c|}
\hline & $\begin{array}{c}\text { Grade } \\
(P \text {-value })\end{array}$ & $\begin{array}{l}\text { Involved } \\
\text { lymph } \\
\text { node } \\
(P \text {-value })\end{array}$ & $\begin{array}{c}\text { PR } \\
\text { status } \\
\text { (P-value) }\end{array}$ & $\begin{array}{c}\text { HER-2 } \\
\text { status } \\
\text { (P-value) }\end{array}$ & $\begin{array}{c}\text { Ki-67 } \\
\text { status } \\
(P \text {-value) }\end{array}$ & $\begin{array}{l}\text { Vascular } \\
\text { invasion } \\
(P \text {-value) }\end{array}$ & $\begin{array}{c}\text { Tumour } \\
\text { lymphocyte } \\
\text { infiltrate } \\
(P \text {-value })\end{array}$ & $\begin{array}{c}\text { Tumour } \\
\text { plasma } \\
\text { cell } \\
\text { infiltrate } \\
\text { (P-value) }\end{array}$ & $\begin{array}{c}\text { Other } \\
\text { inflammatory } \\
\text { cell infiltrate } \\
(P \text {-value })\end{array}$ & $\begin{array}{c}\text { CD68 }+ \\
\text { (P-value) }\end{array}$ \\
\hline Size $(\leqslant 20 / 21-50 />50 \mathrm{~mm})$ & 0.078 & 0.001 & 0.085 & 0.150 & 0.092 & 0.043 & 0.979 & 0.510 & 0.722 & 0.875 \\
\hline Grade $(|/||/|||)$ & & 0.032 & 0.002 & 0.582 & 0.377 & 0.097 & 0.128 & 0.347 & 0.689 & 0.136 \\
\hline Involved lymph node $(0 / 1-3 />3)$ & & & 0.101 & 0.027 & 0.129 & $<0.001$ & 0.143 & 0.110 & 0.571 & 0.820 \\
\hline Progesterone -receptor status $(\mathrm{PR}-/ \mathrm{PR}+)$ & & & & 0.862 & 0.807 & 0.345 & 0.380 & 0.531 & 0.452 & 0.942 \\
\hline HER-2 status (HER-2 - /HER-2 + ) & & & & & 0.920 & 0.002 & 0.780 & 0.832 & 0.750 & 0.659 \\
\hline $\begin{array}{l}\text { Ki-67 proliferative activity } \\
\text { (low Ki-67/high Ki-67) }\end{array}$ & & & & & & 0.837 & 0.096 & 0.070 & 0.223 & 0.121 \\
\hline Vascular invasion (absent/present) & & & & & & & 0.256 & 0.020 & 0.980 & 0.579 \\
\hline $\begin{array}{l}\text { Tumour lymphocyte infiltrate } \\
\text { (low grade/high grade) }\end{array}$ & & & & & & & & $<0.001$ & $<0.001$ & 0.831 \\
\hline $\begin{array}{l}\text { Tumour plasma cell infiltrate } \\
\text { (low grade/high grade) }\end{array}$ & & & & & & & & & 0.001 & 0.743 \\
\hline $\begin{array}{l}\text { Other inflammatory cell infiltrate } \\
\text { (low grade/high grade) }\end{array}$ & & & & & & & & & & 0.054 \\
\hline
\end{tabular}

Abbreviations: $\mathrm{Cl}=$ confidence interval; $\mathrm{ER}=$ oestrogen receptor; $\mathrm{HER}-2$ = human epidermal growth factor receptor-2; $\mathrm{HR}=$ hazard ratio; $\mathrm{PR}=$ progesterone receptor. Bold values indicate $P \leqslant 0.01$.

Table 7 Interrelationships between the clinicopathological characteristics in patients with ER-positive primary operable invasive ductal breast cancer $(n=283)$

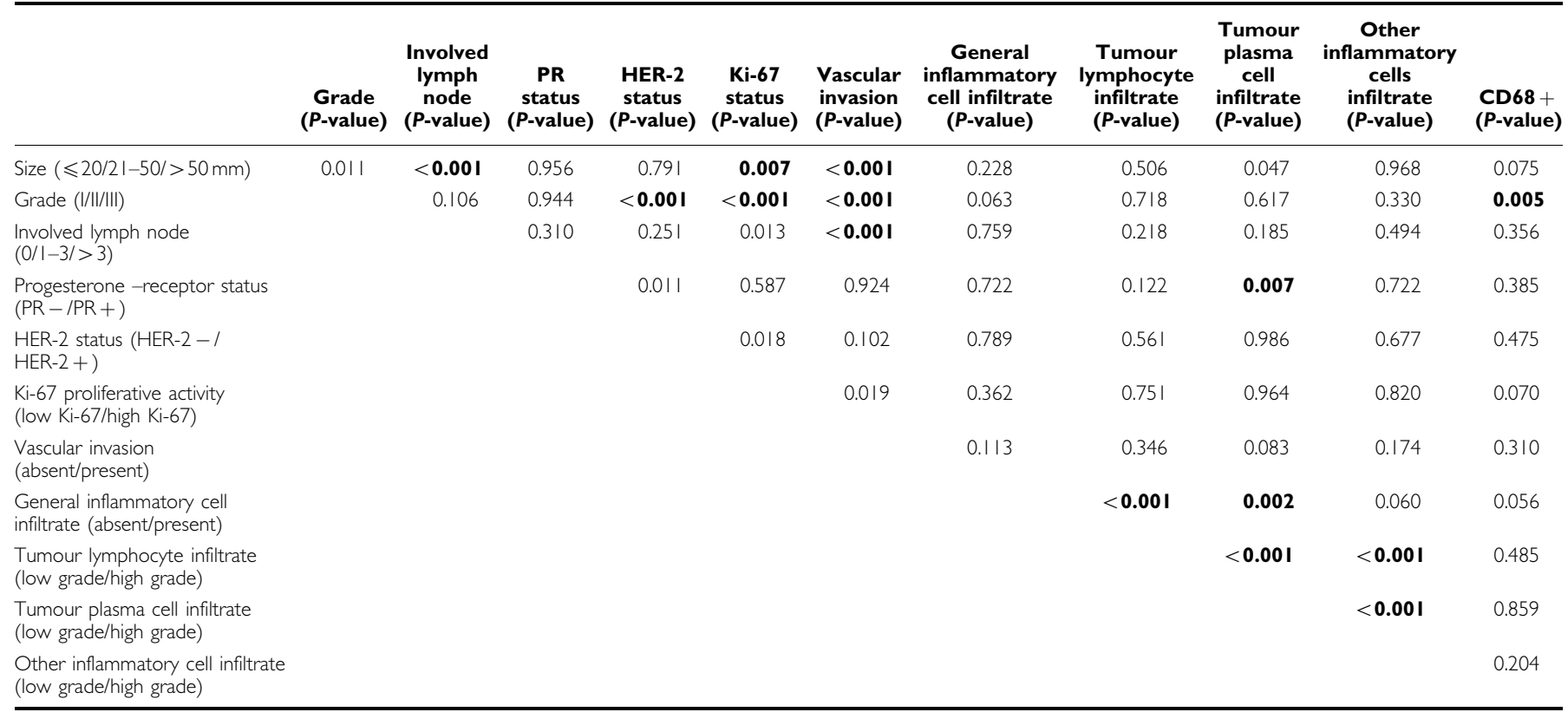

Abbreviations: $\mathrm{Cl}=$ confidence interval; $\mathrm{ER}=$ oestrogen receptor; HER-2 = human epidermal growth factor receptor-2; HR=hazard ratio; $\mathrm{PR}=$ progesterone receptor. Bold values indicate $P \leqslant 0.01$.

$(P<0.001)$. The presence of $\mathrm{PR}$ was negatively associated with plasma cell infiltrate $(P<0.01)$. General inflammatory cell infiltrate was positively associated with lymphocyte infiltrate $(P<0.001)$ and plasma cell infiltrate $(P<0.01)$. Lymphocyte infiltrate was negatively associated with plasma cell infiltrate $(P<0.001)$ and other inflammatory cells infiltrate $(P<0.001)$. Plasma cell infiltrate was positively associated with other inflammatory cells infiltrate $(P<0.001)$.

\section{DISCUSSION}

This study examined, in systematic manner, the clinicopathological nature of the tumour inflammatory cell infiltrate in patients with primary operable invasive ductal breast cancer. The results of this study show that, using routine histology, the general inflammatory cell infiltrate was a common feature and was positively associated with high grade, the absence of ER, the absence of PR, the presence of vascular invasion and high-grade infiltration of lymphocytes, plasma cells, other inflammatory cells and macrophages. Also, that within a mature cohort of patients, a high lymphocytic infiltrate was associated with improved survival, independent of clinicopathological characteristics including ER status, in primary operable ductal invasive breast cancer. These results rationalise previous work and provide a sound basis for future studies in this important area of breast cancer research.

The peritumoural inflammatory response is thought to reflect the interaction between the tumour and the host. Although this 
response has frequently observed using different approaches irrespective of tumour type or ER status (Mohammed et al, $2012 \mathrm{~b}$ ), it has been reported to have either a positive or negative influence on survival. However, the results of this study are consistent with lymphocytes and macrophages being the most prominent tumour infiltrating cells (Rilke et al, 1991; O'Sullivan and Lewis, 1994; Lee et al, 2006; Mahmoud et al, 2012), and that high-grade lymphocytic infiltrate is independently associated with improved survival (Mohammed et al, 2012b). Taken together, these results indicate an important role for inflammatory cell infiltrate and lymphocytic infiltration in patients with primary operable invasive ductal breast cancer. Therefore, further work is required to improve our understanding of lymphocyte phenotypes, their functions and their prognostic potential in patients with ductal invasive breast cancer.

It was also of interest that this study identified that a high plasma cell infiltrate was associated with poorer survival in patients with ER-positive breast cancer. These results are consistent with the concept that, once the tumour is established, B-lymphoctyes may have a negative effect on protective antitumour responses (Dong et al, 2006) and may even facilitate tumour progression (de Visser et al, 2005; DeNardo and Coussens, 2007). Moreover, the activation of B lymphocytes by apoptotic bodies could result in production of cytokines such as IL-10 that can inhibit T-cell responses and promote tumour growth (Harless, 2009). However, there have been conflicting reports regarding the relationship between B-lymphocytes infiltrate and survival in patients with breast cancer (Mohammed et al, 2012b). Two out of five studies, that examined the relationship between B-lymphocytic infiltrate and survival, reported a direct association between high B-lymphocytes infiltrate and improved survival whereas one reported inverse association and the other two reported no association (Mohammed et al, 2012b). Therefore, further work is needed to examine, with more sophisticated techniques, the relationship between tumour T- and B-lymphocytic infiltrate and outcome in patients with breast cancer.

There have also been conflicting reports regarding the relationship between tumour macrophage infiltrate and survival in patients with breast cancer (Mohammed et al, 2012b). Five out of ten studies, that examined the relationship between macrophage infiltrate and survival, reported an inverse association whereas five others reported no association (Mohammed et al, 2012b). More recently, study by Mahmoud et al (2012) reported that high $\mathrm{CD} 68+$ macrophage infiltrate was significantly associated with poorer recurrence-free and cancer-specific survival. However, in multivariate analaysis, this was not independently significant. In contrast, in this study a high tumour macrophage infiltrate was independently associated with improved survival in patients with ER-negative breast cancer. The reasons for such discrepances using similar methodology are not clear, however, there is some evidence that macrophage markers, such as $\mathrm{CD} 68+$ may be expressed by other non-myeloid tissues in cancer (Gottfried et al, 2008).

In this study, it was of interest that it may appear paradoxical that 60 patients with apparently ER-negative tumours received endocrine treatment. However, in the period 1995-1998, the ER status was determined by a ligand-binding assay. As part of this study, patients had their ER status reassessed using IHC. It is likely that some ER + ligand-binding assays were false positives due to non-neoplastic parenchymal cells contaminating ER-negative tumour samples. Similarly, in this study patients were recruited between 1995 and 1998 and although HER-2 status was established, there were no patients who received adjuvant anti-HER-2 therapy. Therefore, given the impact of such treatment on improved survival, it would be of considerable interest, in future studies to specifically examine the relationship between the tumour inflammatory infiltrate and survival in such patients.

In conclusion, the results of this study show that, using routine methods, tumour inflammatory cell infiltrate is a common feature, varies with ER status and grade and, within a mature cohort of patients, a high lymphocytic infiltrate was associated with improved survival, independent of clinicopathological characteristics including ER status, in primary operable ductal invasive breast cancer.

\section{ACKNOWLEDGEMENTS}

We gratefully acknowledged the funding from the Libyan government and the assistant of Miss Clare Orange (Western Infirmary, Glasgow).

\section{REFERENCES}

Cancerstats (2008) http://info.cancerresearchuk.org/cancerstats/types/ breast/incidence. Accessed 25 June 2010

Colotta F, Allavena P, Sica A, Garlanda C, Mantovani A (2009) Cancer-related inflammation, the seventh hallmark of cancer: links to genetic instability. Carcinogenesis 30(7): 1073-1081

de Visser KE, Korets LV, Coussens LM (2005) De novo carcinogenesis promoted by chronic inflammation is B lymphocyte dependent. Cancer Cell 7(5): 411-423

DeNardo DG, Coussens LM (2007) Inflammation and breast cancer. Balancing immune response: crosstalk between adaptive and innate immune cells during breast cancer progression. Breast Cancer Res 9(4): 212

Dong HP, Elstrand MB, Holth A, Silins I, Berner A, Trope CG, Davidson B, Risberg $\mathrm{Br}$ (2006) NK- and B-cell infiltration correlates with worse outcome in metastatic ovarian carcinoma. Am J Clin Pathol 125(3): 451-458

Gasparini G, Weidner N, Bevilacqua P, Maluta S, Dalla Palma P, Caffo O, Barbareschi M, Boracchi P, Marubini E, Pozza F (1994) Tumor microvessel density, p53 expression, tumor size, and peritumoral lymphatic vessel invasion are relevant prognostic markers in nodenegative breast carcinoma. J Clin Oncol 12(3): 454-466

Gottfried E, Kunz-Schughart LA, Weber A, Rehli M, Peuker A, Muller A, Kastenberger M, Brockhoff G, Andreesen R, Kreutz M (2008) Expression of CD68 in non-myeloid cell types. Scand J Immunol 67(5): 453-463
Hanahan D, Weinberg RA (2011) Hallmarks of cancer: the next generation. Cell 144(5): 646-674

Harless WW (2009) Revisiting perioperative chemotherapy: the critical importance of targeting residual cancer prior to wound healing. BMC Cancer 9: 118

Kato T, Kameoka S, Kimura T, Nishikawa T, Kobayashi M (2003) The combination of angiogenesis and blood vessel invasion as a prognostic indicator in primary breast cancer. Br J Cancer 88(12): 1900-1908

Klintrup K, Makinen JM, Kauppila S, Vare PO, Melkko J, Tuominen H, Tuppurainen K, Makela J, Karttunen TJ, Makinen MJ (2005) Inflammation and prognosis in colorectal cancer. Eur J Cancer 41(17): 2645-2654

Lal P, Tan LK, Chen B (2005) Correlation of HER-2 status with estrogen and progesterone receptors and histologic features in 3,655 invasive breast carcinomas. Am J Clin Pathol 123(4): 541-546

Lee AHS, Gillett CE, Ryder K, Fentiman IS, Miles DW, Millis RR (2006) Different patterns of inflammation and prognosis in invasive carcinoma of the breast. Histopathology 48(6): 692-701

Lee AK, DeLellis RA, Silverman ML, Heatley GJ, Wolfe HJ (1990) Prognostic significance of peritumoral lymphatic and blood vessel invasion in node-negative carcinoma of the breast. J Clin Oncol 8(9): 1457-1465

Mahmoud SM, Lee AH, Paish EC, Macmillan RD, Ellis IO, Green AR (2012) Tumour-infiltrating macrophages and clinical outcome in breast cancer. J Clin Pathol 65(2): 159-163 
Mohammed ZM, Edwards J, Orange C, Mallon E, Doughty JC, McMillan DC, Going JJ (2012a) Breast cancer outcomes by steroid hormone receptor status assessed visually and by computer image analysis. Histopathology doi:10.1111/j.1365-2559.2012.04244

Mohammed ZM, Going JJ, Edwards J, McMillan DC (2012b) The role of the tumour inflammatory cell infiltrate in predicting recurrence and survival in patients with primary operable breast cancer. Cancer Treat Rev doi:S0305-7372(12)00109-0 (pii);10.1016/j.ctrv.2012.04.011

Mohammed ZM, McMillan DC, Elsberger B, Going JJ, Orange C, Mallon E, Doughty JC, Edwards J (2012c) Comparison of Visual and automated assessment of Ki-67 proliferative activity and their impact on outcome in primary operable invasive ductal breast cancer. Br J Cancer 106(2): 383-388

Mohammed ZMA, Going JJ, McMillan DC, Orange C, Mallon E, Doughty JC, Edwards J (2012d) Comparison of visual and automated assessment of HER-2 status and their impact on outcome in primary operable invasive ductal breast cancer. Histopathology; e-pub ahead of print 9 April 2012; doi: 10.1111/j.1365-2559.2012.04280.x
O'Sullivan C, Lewis CE (1994) Tumour-associated leucocytes: friends or foes in breast carcinoma. J Pathol 172(3): 229-235

Parkin DM, Bray F, Ferlay J, Pisani P (2001) Estimating the world cancer burden: Globocan 2000. Int J Cancer 94(2): 153-156

Rilke F, Colnaghi MI, Cascinelli N, Andreola S, Baldini MT, Bufalino R, Della PG, Menard S, Pierotti MA, Testori A (1991) Prognostic significance of HER-2/neu expression in breast cancer and its relationship to other prognostic factors. Int J Cancer 49(1): 44-49

Roxburgh CSD, Salmond JM, Horgan PG, Oien KA, McMillan DC (2009a) Comparison of the prognostic value of inflammation-based pathologic and biochemical criteria in patients undergoing potentially curative resection for colorectal cancer. Ann Surg 249(5): 788-793

Roxburgh CSD, Salmond JM, Horgan PG, Oien KA, McMillan DC (2009b) Tumour inflammatory infiltrate predicts survival following curative resection for node-negative colorectal cancer. Eur J Cancer 45(12): 2138-2145

Vakkila J, Lotze MT (2004) Inflammation and necrosis promote tumour growth. Nat Rev Immunol 4(8): 641-648

This work is published under the standard license to publish agreement. After 12 months the work will become freely available and the license terms will switch to a Creative Commons Attribution-NonCommercial-Share Alike 3.0 Unported License. 